\title{
Seroprevalence of Hepatitis C Virus (HCV) and Hepatitis B Virus (HBV) In District Vehari, Pakistan
}

\author{
Muhammad Zeeshan Ahmed ${ }^{1,2}$, Haseeba Shahzad ${ }^{1}$, Tazeen Rao ${ }^{1}$, Aleema Ali $^{1}$ and Noreen Samad ${ }^{1}$ \\ ${ }^{1}$ Department of Biochemistry, Bahauddin Zakariya University, Multan, Pakistan \\ ${ }^{2}$ Institute of Biochemistry and Biotechnology, University of The Punjab, Quaid-I-Azam Campus, Lahore, Pakistan
}

\begin{abstract}
The aim of the study was to evaluate the prevalence of hepatitis C virus (HCV) and hepatitis B virus (HBV) in district Vehari, Pakistan; and to highlight the alarming situation of HCV. This survey was conducted in the district from June to August 2018 . A total of $697(72.99 \%)$ cases out of 955 , were found to be infected with hepatitis viruses, among which, $681(71.3 \%)$ were infected with $\mathrm{HCV}$ and 16 (1.68\%) with HBV. HCV was found more prevalent in females while more cases of HBV were reported in males. Overall age ranged from 31 to 60 years, with females from 51-60 years; infected with HCV and HBV in male with age range 19-30 years infected with HBV. The situation of the seroprevalence of HCV is alarming and the authorities in Pakistan should take extensive measures for the elimination of the hepatitis viruses from Pakistan.
\end{abstract}

Key Words: Seroprevalence, Hepatitis C virus, Hepatitis B virus, Pakistan.

How to cite this article: Ahmed MZ, Shahzad H, Rao T, Ali A, Samad N. Seroprevalence of Hepatitis C Virus (HCV) and Hepatitis B Virus (HBV) In District Vehari, Pakistan. J Coll Physicians Surg Pak 2020; 30(05):550-551. DOI: https://doi.org/10.29271/jcpsp.2020.05.550.

Hepatitis is an inflammatory disorder of the liver, caused by five types of viruses: hepatitis A virus (HAV), hepatitis B virus (HBV), hepatitis $C$ virus (HCV), hepatitis D virus (HDV), and hepatitis $E$ virus (HEV). Among these viruses, HBV and HCV are the most common having $96 \%$ mortality rate. HCV and HBV lead to liver cancer. World Health Organization (WHO) is forcing and joining all countries on World Hepatitis Day to eradicate hepatitis completely by 2030. Pakistan is the second country in the world having 8 million (5\%) cases of hepatitis C; in other words, one out of every 20 people had infected liver, reported in 2018. in addition, 7 to 9 million HBV carriers are present in Pakistan. ${ }^{1,2}$

Due to poor health and limited access to clinical symptoms of the disease, it is not possible to estimate the prevalence of hepatitis in Pakistan. However, Pakistan is now working on controlling hepatitis with legislation and investment that will ensure positive results in the future. On $21^{\text {st }}$ December 2018, Pakistan organised three-days' workshop by the team of WHO to discuss strategies to completely eliminate hepatitis. ${ }^{3}$ This study discussed the prevalence of $\mathrm{HCV}$ and HBV in the district Vehari of Punjab, Pakistan.

We collected reports from North Shore Medical Laboratory, in district headquarters Hospital, Vehari from June to August 2018with the consent of patients. The patients with symptoms of jaundice and recommended by their physicians were included in this study; $3 \mathrm{ml}$ of venous blood was collected and stored in vials containing sodium citrate.

Correspondence to: Noreen Samad, Department of Biochemistry, Bahauddin Zakariya University, Bosan Road, Multan, Pakistan

E-mail: noreen.samad@bzu.edu.pk

.

Received: February 21, 2020; Revised: June 01, 2020;

Accepted: June 01, 2020

DOI: https://doi.org/10.29271/jcpsp.2020.05.550
Serum was obtained after centrifugation and used for the qualitative detection of HBsAg and HCV antibodies using HBV and HBC rapid test (cassette) which is lateral flow chromatographic immunoassay ${ }^{4}$ as per laboratory protocol. The study was approved by Departmental Bioethical Committee (D/1890/2018/ Biochem; Dated 19/06/2018). All the data were arranged on the excel spread sheet and then analysed in the SPSS version 21 with a significant difference of $p<0.01$. Frequencies and percentages were obtained, and a table was formulated (Tablel).

In 2009, 7.4\% prevalence of hepatitis B and C was recorded in the total population of Pakistan. In the same year, Pakistan Medical Research Council (PMRC) reported 4.9\% HCV and 2.5\% HBV infected cases. ${ }^{5}$ In this study, $71.3 \%$ cases of HCV and $1.68 \%$ cases of HBV were found in district Vehari, Pakistan. Among these, $336(35.19 \%)$ were males and 361 (37.8\%) females infected with hepatitis viruses. In this study, females (37.38\%) were more HCV positive while males (1.26\%) were more HBV positive. Our results for HCV and HBV in terms of gender, are similartotheresultsreported by Munir et al. ${ }^{6}$ for the Hazara division, Pakistan. ${ }^{6}$ According to the age groups and gender, more hepatitis cases were found in the overall age 31 to 60 years group, while 51 to 60 years age group had more cases, 91 (9.52\%) of females and 81 (8.5\%) of males. Age group from 19 to 30 years had more HBV positive cases, in which $5(0.53 \%)$ were males and $2(0.21 \%)$ were females. In this study, only one $(0.1 \%)$ case of HBV in the male from the age of 1 to 15 years was reported. Major causes of hepatitis in Pakistan are the transfusion of blood, contaminated surgical instruments, and reuse of injections. Illiteracy, poverty, lack of knowledge, and moral issues predispose to this high-risk behaviour. ${ }^{4}$

A huge burden and difficulties in detecting the silent cases and uncontrolled epidemic of the hepatitis viruses in Pakistan are the major challenges for the public health experts in this country. 
Table I: Frequencies of hepatitis B and hepatitis C viruses in both genders and in different age groups.

\begin{tabular}{|c|c|c|c|c|c|c|c|c|c|c|c|c|c|c|}
\hline & \multicolumn{2}{|c|}{ Study population } & \multicolumn{2}{|c|}{ Positive for hepatitis } & \multicolumn{2}{|c|}{ Negative for hepatitis } & \multicolumn{2}{|c|}{ Positive for hepatitis C } & \multicolumn{2}{|c|}{ Negative for hepatitis C } & \multicolumn{2}{|c|}{$\begin{array}{l}\text { Positive for } \\
\text { hepatitis B }\end{array}$} & \multicolumn{2}{|c|}{ Negative for hepatitis $B$} \\
\hline & $\mathbf{N}$ & $\%$ & $\mathbf{n}$ & $\%$ & $\mathbf{n}$ & $\%$ & $\mathbf{n}$ & $\%$ & $\mathbf{n}$ & $\%$ & $\mathbf{n}$ & $\%$ & $\mathbf{n}$ & $\%$ \\
\hline Total & 955 & 100 & 697 & 72.99 & 258 & 27.01 & 681 & 71.3 & 274 & 28.7 & 16 & 1.68 & 939 & 98.32 \\
\hline \multicolumn{15}{|l|}{ Gender } \\
\hline Male & 464 & 48.58 & 336 & 35.19 & 128 & 13.4 & 324 & 33.92 & 140 & 14.66 & 12 & 1.26 & 452 & 47.32 \\
\hline Female & 491 & 51.41 & 361 & 37.8 & 130 & 13.61 & 357 & 37.38 & 134 & 14.04 & 4 & 0.42 & 487 & 51 \\
\hline \multicolumn{15}{|c|}{ Age groups and gender - $1^{\text {st }}$ day to $6^{\text {th }}$ months } \\
\hline Male & 10 & 1.04 & 2 & 0.21 & 8 & 0.84 & 2 & 0.21 & 8 & 0.84 & 0 & 0 & 10 & 1.05 \\
\hline Female & 8 & 0.84 & 0 & 0 & 8 & 0.84 & 0 & 0 & 8 & 0.84 & 0 & 0 & 8 & 0.84 \\
\hline \multicolumn{15}{|c|}{$6^{\text {th }}$ months to 9 years } \\
\hline Male & 15 & 1.57 & 1 & 0.104 & 14 & 1.46 & 1 & 0.104 & 14 & 1.46 & 0 & 0 & 15 & 1.57 \\
\hline Female & 17 & 1.8 & 4 & 0.42 & 13 & 1.36 & 4 & 0.42 & 13 & 1.36 & 0 & 0 & 17 & 1.8 \\
\hline \multicolumn{15}{|c|}{10 - 18 years } \\
\hline Male & 65 & 6.8 & 50 & 5.23 & 15 & 1.55 & 49 & 5.13 & 16 & 1.67 & 1 & 0.104 & 64 & 6.7 \\
\hline Female & 61 & 6.38 & 50 & 5.23 & 11 & 1.17 & 50 & 5.23 & 11 & 1.17 & 0 & 0 & 61 & 6.38 \\
\hline \multicolumn{15}{|c|}{19 - 30 years } \\
\hline Male & 66 & 6.94 & 49 & 5.13 & 17 & 1.8 & 44 & 4.616 & 22 & 2.3 & 5 & 0.53 & 61 & 6.38 \\
\hline Female & 74 & 7.74 & 57 & 5.97 & 17 & 1.8 & 55 & 5.76 & 19 & 2 & 2 & 0.21 & 72 & 7.53 \\
\hline \multicolumn{15}{|c|}{31 - 40 years } \\
\hline Male & 97 & 10.15 & 71 & 7.43 & 26 & 2.7 & 68 & 7.12 & 29 & 3.02 & 3 & 0.314 & 94 & 9.84 \\
\hline Female & 90 & 9.43 & 73 & 7.65 & 17 & 1.8 & 72 & 7.54 & 18 & 1.88 & 1 & 0.104 & 89 & 9.32 \\
\hline \multicolumn{15}{|c|}{41 - 50 years } \\
\hline Male & 101 & 10.57 & 76 & 7.96 & 25 & 2.6 & 74 & 7.75 & 27 & 2.836 & 2 & 0.21 & 99 & 10.37 \\
\hline Female & 106 & 11.1 & 83 & 8.7 & 23 & 2.4 & 82 & 8.59 & 24 & 2.52 & 1 & 0.104 & 105 & 11 \\
\hline \multicolumn{15}{|c|}{51 - 60 years } \\
\hline Male & 101 & 10.57 & 81 & 8.5 & 20 & 2.09 & 80 & 8.37 & 21 & 2.2 & 1 & 0.104 & 100 & 10.47 \\
\hline Female & 123 & 12.88 & 91 & 9.52 & 32 & 3.35 & 91 & 9.52 & 32 & 3.35 & 0 & 0 & 123 & 12.88 \\
\hline \multicolumn{15}{|c|}{ More than 60 years } \\
\hline Male & 9 & 0.94 & 6 & 0.63 & 3 & 0.314 & 6 & 0.63 & 3 & 0.314 & 0 & 0 & 9 & 0.94 \\
\hline Female & 12 & 1.25 & 3 & 0.31 & 9 & 0.94 & 3 & 0.31 & 9 & 0.94 & 0 & 0 & 12 & 1.25 \\
\hline
\end{tabular}

Moreover, its treatment is expensive, making it difficult to treat properly a very large number of patients in public health services. Therefore, huge efforts are needed by the adminis-tration for controlling the epidemic of hepatitis in Pakistan.

\section{CONFLICT OF INTEREST:}

Authors declared that there is no conflict of interest related to this study.

\section{AUTHORS' CONTRIBUTION:}

MZA: Data collection, statistical analysis and manuscript writing.

HS, TR, AA: Data collection and literature review.

NS: Manuscript writing and final draft.

\section{REFERENCES}

1. Lim AG, Qureshi H, Mahmood H, Hamid S, Davies CF, Trickey A et al. Curbing the hepatitis $C$ virus epidemic in Pakistan: The impact of scaling up treatment and prevention for achieving elimination. Int J Epidemiol 2018; 47:550-60.

2. Al Kanaani Z, Mahmud S, Kouyoumjian SP, Abu-Raddad LJ. The epidemiology of hepatitis C virus in Pakistan: Systematic review and meta-analyses. $R$ Soc Open Sci 2018; 5:180257.

3. WHO | Pakistan's investment in hepatitis may see return within years. WHO 2018.http://www.who.int/hepatitis/ newsevents/towards-hepatitis-elimination-pakistan/en/ (accessed 15 Jan2019).

4. Akhtar H, Badshah Y, Akhtar S, Hasan F, Faisal M, Zaidi NUSS et al. Prevalence of hepatitis $B$ and hepatitis $C$ Virus infections among male to female (MFT) transgenders in Rawalpindi (Pakistan). Adv LIFE Sci 2018; 5:46-55.

5. Qasim M. Prevalence of hepatitis B \& C in Pakistan assessed. News. 2010.http://www.thenews.com.pk/archive/print/214975-prevalence-of-hepatitis-b-\&-c-in-pakistan-assessed) (accessed 20 Jan2019).

6. Munir A, Azam S, Shah G. Prevalence of hepatitis B virus and hepatitis $C$ virus among inhabtants of Hazara division, Pakistan. Int J Biotechnol Allied Fields 2016; 4:421-31. 